\title{
Endosomal Compartments Serve Multiple Hippocampal Dendritic Spines from a Widespread Rather Than a Local Store of Recycling Membrane
}

\author{
James R. Cooney, Jamie L. Hurlburt, David K. Selig, Kristen M. Harris, and John C. Fiala \\ Department of Biology, Boston University, Boston, Massachusetts 02215
}

Endosomes are essential to dendritic and synaptic function in sorting membrane proteins for degradation or recycling, yet little is known about their locations near synapses. Here, serial electron microscopy was used to ascertain the morphology and distribution of all membranous intracellular compartments in distal dendrites of hippocampal CA1 pyramidal neurons in juvenile and adult rats. First, the continuous network of smooth endoplasmic reticulum (SER) was traced throughout dendritic segments and their spines. SER occupied the cortex of the dendritic shaft and extended into $14 \%$ of spines. Several types of non-SER compartments were then identified, including clathrin-coated vesicles and pits, large uncoated vesicles, tubular compartments, multivesicular bodies (MVBs), and MVBtubule complexes. The uptake of extracellular gold particles indicated that these compartments were endosomal in origin. Small, round vesicles and pits that did not contain gold were also identified. The tubular compartments exhibited clathrincoated tips consistent with the genesis of these small, presumably exosomal vesicles. Approximately $70 \%$ of the non-SER compartments were located within or at the base of dendritic spines. Overall, only $29 \%$ of dendritic spines had endosomal compartments, whereas $20 \%$ contained small vesicles. Small vesicles did not colocalize in spines with endosomes or SER. Three-dimensional reconstructions revealed that up to 20 spines shared a recycling pool of plasmalemmal proteins rather than maintaining independent stores at each spine.

Key words: apical dendrites; clathrin; coated bud; dendritic spine; early endosome; endocytosis; exocytosis; hippocampus; long-term depression; long-term potentiation; multivesicular body; receptor recycling; smooth endoplasmic reticulum; sorting endosome; spine apparatus; stratum radiatum; synapse; tubular endosome
Recent studies have shown that postsynaptic endocytosis and exocytosis serve important roles in long-term depression (LTD) and long-term potentiation (LTP) at hippocampal synapses (Carroll et al., 1999; Lüscher et al., 1999; Shi et al., 1999; Hayashi et al., 2000; Man et al., 2000). Blocking exocytosis prevents the induction of LTP, whereas blocking endocytosis prevents the induction of LTD. The evidence supports a mechanism of synaptic plasticity in which glutamate receptors are rapidly removed from and inserted into the postsynaptic membrane within minutes of synaptic stimulation (Ehlers, 2000). Such a mechanism suggests that stores of receptors are maintained intracellularly, in organelles capable of rapid delivery to synapses (Ehlers, 2000; Lin et al., 2000; Carroll et al., 2001; Sheng and Lee, 2001). A popular model has been that endosomes provide a local store of receptors at individual dendritic spines. However, relatively little is known about the distribution of endosomal organelles in distal dendrites where most synapses are located (Lüscher and Frerking, 2001).

Excitatory synapses in stratum radiatum of hippocampal area CA1 occur on dendritic spines. These dendritic spines contain at least two different types of membranous intracellular compartments: smooth endoplasmic reticulum (SER) and tubulovesicular

\footnotetext{
Received Aug. 14, 2001; revised Dec. 5, 2001; accepted Dec. 28, 2001.

This work was supported by National Institutes of Health Grants NS21184 and NS33574, and Human Brain Project Grant MH/DA57351 funded jointly by the National Institute of Mental Health and the National Institute on Drug Abuse. Thanks to Brenda Allwardt and Alex Goddard for preparation of some of the slices for analysis. Thanks to Marcia Feinberg for serial sectioning and electron microscopy.

Correspondence should be addressed to Dr. John Fiala, Department of Biology, 5 Cummington Street, Boston University, Boston, MA 02215. E-mail: fiala@bu.edu. Copyright (C) 2002 Society for Neuroscience $0270-6474 / 02 / 222215-10 \$ 15.00 / 0$
}

compartments (Spacek and Harris, 1997). Previous ultrastructural studies included the tubulovesicular compartments in estimating the distribution of SER in dendrites. However, the tubulovesicular compartments include endosomes and other organelles possibly involved in receptor storage and trafficking. In the present study, SER and non-SER compartments were treated separately, thereby allowing a detailed characterization of the three-dimensional structure and distribution of endosomes.

\section{MATERIALS AND METHODS}

All procedures followed National Institutes of Health guidelines and undergo yearly review by the Animal Care and Use Committee at Boston University. Serial section electron micrographs of perfusion-fixed hippocampi were obtained from previous studies (Harris and Stevens, 1989 Kirov et al., 1999). These hippocampi of Long-Evans male rats (21 and $77 \mathrm{~d}$ old) were fixed in situ under deep pentobarbital anesthesia by intracardiac perfusion with $2.5-6 \%$ glutaraldehyde, $2 \%$ paraformaldehyde, $100 \mathrm{~mm}$ cacodylate buffer, $1 \mathrm{mM} \mathrm{CaCl}_{2}, 2 \mathrm{mM} \mathrm{MgCl}_{2}$, at $\mathrm{pH}$ 7.4.

Acute hippocampal slices were prepared from 15- and 21-d-old LongEvans male rats by dissecting out the hippocampus and cutting $400 \mu \mathrm{m}$ slices $70^{\circ}$ transverse to the long axis from the middle third of the hippocampus with a cold tissue chopper (Stoelting Co., Wood Dale, IL). Slices were then incubated at $32^{\circ} \mathrm{C}$ at the interface of physiological saline containing (in mM): $117 \mathrm{NaCl}, 5.3 \mathrm{KCl}, 26 \mathrm{NaHCO}_{3}, 1 \mathrm{NaH}_{2} \mathrm{PO}_{4}, 2.5$ $\mathrm{CaCl}_{2}, 1.3 \mathrm{MgSO}_{4}$, and 10 glucose, at $\mathrm{pH} \mathrm{7.4}$, and humidified $95 \%$ $\mathrm{O}_{2}-5 \% \mathrm{CO}_{2}$. After 3-5 hr, slices were fixed in $6 \%$ glutaraldehyde, $2 \%$ paraformaldehyde, $100 \mathrm{~mm}$ cacodylate buffer, $1 \mathrm{~mm} \mathrm{CaCl}_{2}, 2 \mathrm{mM} \mathrm{MgCl}$, at $\mathrm{pH}$ 7.4, using microwave processing (Jensen and Harris, 1989).

One additional slice was prepared from an 18-d-old Long-Evans male rat. This slice was incubated in an interface chamber at $25^{\circ} \mathrm{C}$ for $1 \mathrm{hr}$ in artificial CSF (ACSF) containing (in $\mathrm{mm}$ ): $119 \mathrm{NaCl}, 2.5 \mathrm{KCl}, 26.2$ $\mathrm{NaHCO}_{3}, 1.3 \mathrm{NaH}_{2} \mathrm{PO}_{4}, 2.5 \mathrm{CaCl}_{2}, 1.3 \mathrm{MgSO}_{4}$, and 11 glucose, bubbled with $95 \% \mathrm{O}_{2}-5 \% \mathrm{CO}_{2}$. The slice was then transferred to a submersion chamber and superfused at $5 \mathrm{ml} / \mathrm{min}$ with ACSF pregassed with $95 \%$ 


\begin{tabular}{|c|c|c|c|c|c|c|c|c|c|}
\hline Age & Animals & Segments & Total length & Spines & Thin & Sessile & Mushroom & Stubby & Branched \\
\hline P15 & 1 & 6 & 34.5 & 41 & 20 & 10 & 3 & 5 & 1 \\
\hline $\mathrm{P} 21$ & 6 & 12 & 85.0 & 229 & 136 & 26 & 24 & 24 & 13 \\
\hline Adult & 1 & 7 & 39.6 & 96 & 80 & 4 & 6 & 1 & 5 \\
\hline
\end{tabular}

$\mathrm{O}_{2}-5 \% \mathrm{CO}_{2}$ and maintained at $25^{\circ} \mathrm{C}$. Stimulating and recording electrodes were placed $330 \mu \mathrm{m}$ apart, and stimulation was given every $30 \mathrm{sec}$. After obtaining a stable baseline response, three stimuli consisting of 600 pulses at $1 \mathrm{~Hz}$ were given at 20 min intervals. Forty minutes after the end of the last stimulus, $25 \mu \mathrm{M}$ of colloidal gold-bovine serum albumin (BSA) solution (see below) was ejected into the extracellular space surrounding the recording electrode using a large-tipped $(20 \mu \mathrm{m})$ patch pipette and 5 $\mathrm{cm} \mathrm{H}_{2} \mathrm{O}$ positive pressure. After $15 \mathrm{~min}$, five stimuli consisting of 900 pulses at $10 \mathrm{~Hz}$ were given at $5 \mathrm{~min}$ intervals in the presence of $50 \mu \mathrm{m}$ D-AP5 (Tocris Cookson, Inc., Ellisville, MO). After the final $10 \mathrm{~Hz}$ stimulus, the pipette containing gold was removed, and the slice was stimulated every $2.5 \mathrm{~min}$ for an additional $45 \mathrm{~min}$ to monitor recovery of the response. The applied stimuli were not specifically designed to aid in loading the endosomal compartment, but they may have contributed to that loading. The slice was then fixed in $6 \%$ glutaraldehyde, $2 \%$ paraformaldehyde, $100 \mathrm{~mm}$ cacodylate buffer, $\mathrm{pH}$ 7.4, using microwave processing.

Colloidal gold (3-4 nm) was synthesized according to the methods of Slot and Geuze (1985) and purified and concentrated in water using a Microcon YM-50 centrifugal filter (Millipore Corporation, Bedford, MA). The colloidal gold was combined with BSA (immunohistochemical grade; Vector Labs, Burlingame, $\mathrm{CA}$ ) in the approximate molar ratio of 1:8. The colloidal gold-BSA solution was then subjected to $0.6 \% \mathrm{H}_{2} \mathrm{O}_{2}$ to neutralize any remaining tannic acid. The colloidal gold-BSA solution was purified and concentrated in a Microcon YM-100 centrif ugal filter using HEPES-buffered ACSF consisting of (in mM): $119 \mathrm{NaCl}, 2.5$ $\mathrm{KCl}, 26.2$ HEPES, $1.3 \mathrm{NaH}_{2} \mathrm{PO}_{4}, 2.5 \mathrm{CaCl}_{2}, 1.3 \mathrm{MgSO}_{4}$, and 11 glucose, $\mathrm{pH} 7.4$.

The fixed tissue was processed for electron microscopy using standard procedures (Kirov et al., 1999; Feinberg et al., 2001). The tissue was processed in potassium ferrocyanide-reduced osmium, osmium, and aqueous uranyl acetate and dehydrated with ethanol or acetone using a sequence of increasing concentrations. Infiltration with either Epon only or a mixture of one-to-one Epon-Spurr's resins was done in acetone with $15 \mathrm{~min}$ of microwave processing or with ethanol overnight. This was followed by final infiltrations with either Epon or Epon-Spurr's mixture. Embedded tissue blocks were cured in coffin molds or Beem capsules for $2 \mathrm{~d}$ in a $60^{\circ} \mathrm{C}$ oven. The microwave-enhanced processing and handprocessing methods were indistinguishable in final ultrastructural quality. Slices maintained in the interface chamber appeared ultrastructurally similar to hippocampi fixed in situ (Kirov et al., 1999).

Ultrathin sections were cut from the middle of stratum radiatum at a distance of $250 \mu \mathrm{m}$ from the CA1 cell body layer. Sections were mounted on Pioloform-coated Synaptek slot grids (Ted Pella Inc.) and stained with saturated ethanolic uranyl acetate and Reynold's lead citrate for 5 min each. Series of 70-120 sections, 50-60 nm thick, were cut from each block for a total of 12 series. Series were photographed onto $3 \times 4$ inch film at $10,000 \times$ magnification on the JEOL $1200 \mathrm{EX}$ electron microscope (JEOL USA, Peabody, MA). Negatives were digitized at 1000 dots per inch (dpi) using an AGFA T-2500 electronic scanner (Agfa-Gevaert, Mortsel, Belgium). A diffraction grating replica grid $(0.463 \mu \mathrm{m}$ per square; Ernest Fullam Inc., Latham, NY) was photographed and scanned with each series to allow accurate calibration of dimensions.

In the case of the gold-labeled slice, ultrathin sections were cut from stratum radiatum to include an area $5 \mu \mathrm{m}$ away from the gold electrode tip, $\sim 120 \mu \mathrm{m}$ from the CA1 cell body layer. To optimize viewing of gold particles, sections were stained only with an aqueous solution of $10 \%$ ethanol and $2 \%$ phosphotungstic acid, and a series was cut at $45 \mathrm{~nm}$ section thickness. The series of 71 sections was photographed at $15,000 \times$ on the JEOL 2010 electron microscope and scanned at $2000 \mathrm{dpi}$.

Each series was aligned using sEM Align software and objects were traced using IGL Trace software (Fiala and Harris, 2001a) (freely available at http://synapses.bu.edu/). The section thickness was estimated for each series by the cylindrical diameters method, which involves measuring longitudinally sectioned mitochondria at their maximum diameter in single sections and then counting the number of sections in which the mitochondria appear (Fiala and Harris, 2001b). Section thicknesses fell within the range of 45-65 nm, as determined from 15-30 mitochondria per series.

Aligned series contained many lateral branches of apical dendrites. An unbiased stereological method, namely serial reconstruction through many sections, was used for all analyses (Fiala and Harris, 2001a). All dendrites meeting the criterion of having a diameter $<1 \mu \mathrm{m}$ were identified on the central section of each series. A subset of these candidates were chosen at random from the central section and traced through the entire series, without knowledge that these would be used for analyses of organelle distributions. All protrusions from the dendrite shaft were identified and classified according to shape (Harris et al., 1992). Thin spines had small heads (diameter $<0.6 \mu \mathrm{m}$ ) and a thinner neck constriction. Mushroom spines had large heads (diameter $\geq 0.6 \mu \mathrm{m}$ ) and a neck constriction. Spines without a neck constriction were classified as stubby when their length was less than their width, and as sessile otherwise. Branched spines had multiple heads originating from a single neck. A few spines fell outside these shape categories. To determine spine density on individual segments, spine origins contacting the starting section of the segment were excluded (Fiala and Harris, 2001a). Lengths were measured either within the plane of the section or across serial sections using IGL Trace.

In every reconstructed dendrite, SER was identified on the basis of appearance (flattened cisternae with wavy membrane and clear lumen) and on its continuity with SER compartments on adjacent sections. The volumes and surface areas of dendrites and SER were calculated from the traced profiles by IGL Trace. For determining the fraction of spines containing SER, only those spines on the reconstructed dendrites that were completely contained within the series were used.

After SER was traced throughout the entire dendrite segment, all remaining membranous intracellular compartments were identified and traced. These were classified on the basis of the morphological criteria described in Results. Vesicles were distinguished from tubules by examining adjacent sections. To determine object sizes, profiles were traced on every section, and volumes were computed using IGL Trace. The frequency of object occurrence per $10 \mu \mathrm{m}$ was calculated by dividing the total number of occurrences from all segments by the sum of segment lengths. For surface area ratios, the sum of all specified compartment surface areas was divided by the sum of the surface area of all dendritic segments in the series. Similar calculations were used for volume ratios. For spine percentages, again only complete spines were considered. The number of vesicles per multivesicular body (MVB) was determined by counting clearly transected vesicles on each section.

Three-dimensional surface reconstructions produced from section profiles by IGL Trace were exported to 3D Studio MAX (Discreet Logic, Montreal, Canada) for rendering. ANOVAs followed by Tukey's Unequal N Honest Significant Differences (HSD) tests were done with the STATISTICA software package (StatSoft, Tulsa, OK). Values given in the results are means and SEMs. $\chi^{2}$ tests were computed in Excel (Microsoft, Redmond, CA).

\section{RESULTS}

The endoplasmic reticulum was reconstructed in segments of CA1 pyramidal cell dendrites using ultrathin serial section electron microscopy. Analysis was restricted to lateral branches (diameter $<1 \mu \mathrm{m}$ ) of the apical dendrites in stratum radiatum 250 $\mu \mathrm{m}$ from the cell body layer. Dendrites were analyzed from three ages: $15 \mathrm{~d}$ old (P15), $21 \mathrm{~d}$ old (P21), and $77 \mathrm{~d}$ old (adult). SER was reconstructed in 25 dendritic segments, totaling $159 \mu \mathrm{m}$ in length and containing 366 complete spines for analysis (Table 1). Dendritic spines were classified into five categories based on shape: 
thin, sessile, mushroom, stubby, and branched. The dendritic segments of adult and P21 rats had more spines than P15 dendrites $(3.43 \pm 0.33$ and $2.95 \pm 0.14$ versus $1.53 \pm 0.22$ per micrometer of length; HSD; $p<0.002)$, with proportionally more thin spines in adult than in P21 and P15 $\left(\chi^{2} ; p<0.001\right.$ and $p<$ $0.00005)$. Although dendritic protrusions occasionally did not receive synaptic contacts, $>94 \%$ had synapses on their heads at all of the ages.

Adult dendrites had more total surface area than P15 dendrites (4.66 \pm 0.45 versus $3.02 \pm 0.5 \mu \mathrm{m}^{2}$ per micrometer of length; HSD; $p<0.02)$, whereas P21 dendrites had an intermediate amount (3.63 $\pm 0.18 \mu \mathrm{m}^{2}$ per micrometer of length) not significantly different from the other ages. Dendritic spines accounted for half $(48 \pm 2.6 \%)$ of the dendritic surface area in the adult dendritic segments. The proportion of dendritic surface area for spines was less at P21 (39 $\pm 1.3 \%)$ and P15 (29 $\pm 1.7 \%)$.
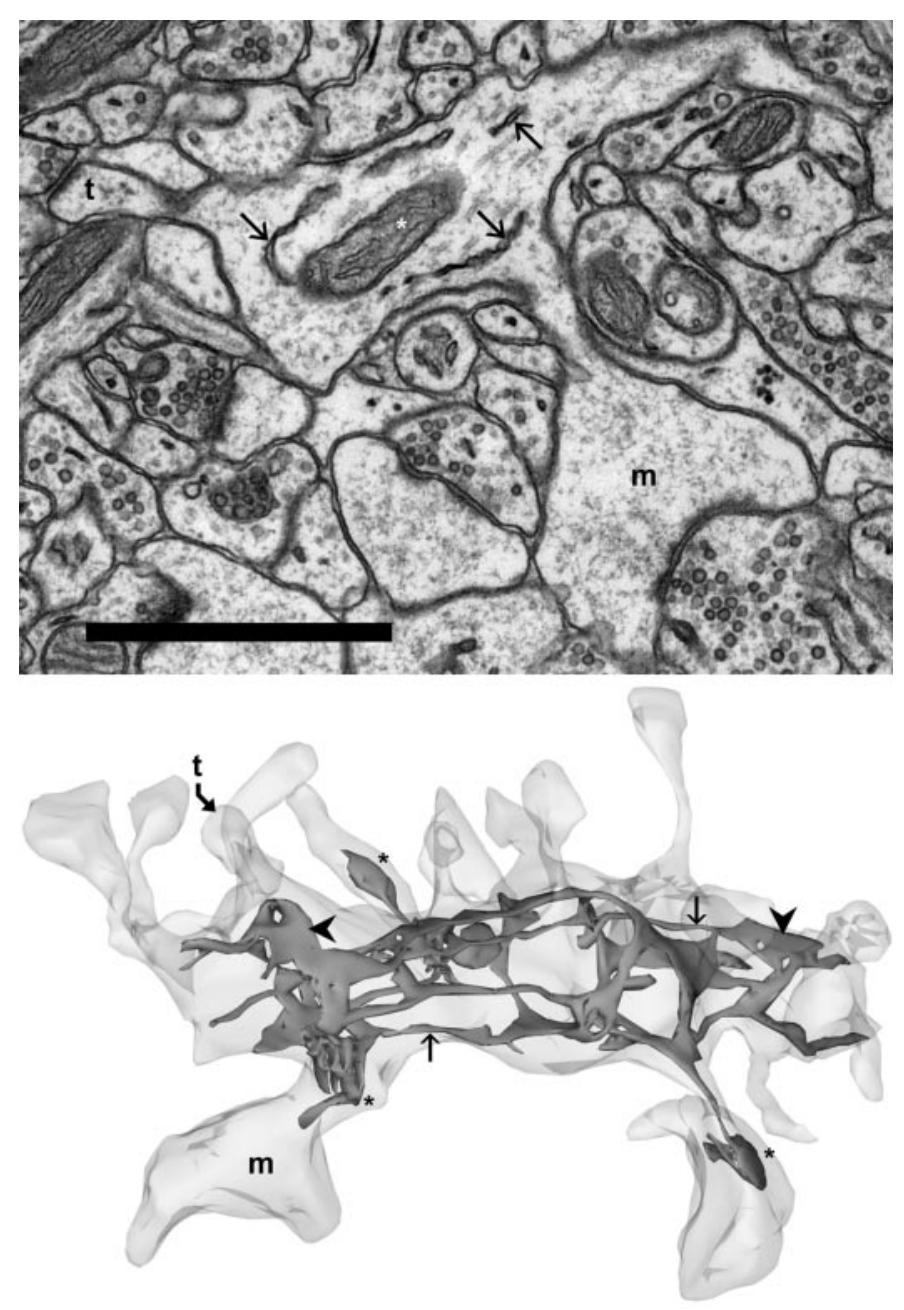

Figure 1. Smooth endoplasmic reticulum forms a network in the dendrite. Top, SER in a single section appears as thin cisternae with wavy membranes (arrows) surrounding a mitochondrion (*). A mushroom spine $(m)$ and a thin spine $(t)$ originate from the dendrite on this section. Bottom, Three-dimensional reconstruction of the SER demonstrates that the cisternae form a network with larger flat compartments (arrowheads) connected by thin extensions (arrows). Most of the network lies in the periphery of the dendrite, surrounding the mitochondria (not shown in reconstruction). Seventeen spines originate from this segment of dendrite. SER is found in only three spines (*), two of which are large mushroom spines with spine apparatuses. Scale bar, $1.0 \mu \mathrm{m}$.

\section{Distribution of SER}

Three-dimensional reconstructions revealed that SER at all ages was mainly a network of thin tubules (diameter $<0.04 \mu \mathrm{m}$ ) that occasionally widened into larger cisternae (Fig. 1). The tubules and cisternae generally were flattened, with a wavy membrane. Where the lumen of the SER was visible, it was electron lucent. SER was generally located in the cortex of the dendritic cytoplasm, with thin branches intermittently traversing the cytoplasm to connect with other parts of the network. SER was also continuous with the outer membrane of some mitochondria as described previously by Spacek and Lieberman (1980). No obvious association of SER with dendritic microtubules could be discerned.

Because of the generally flattened nature of the SER, the volume of SER was a relatively small fraction of the total dendrite volume $(3.2 \pm 0.2 \%)$. This fraction was not significantly different between ages. The surface area of the SER ranged from 13 to $49 \%$ (mean: $26 \pm 2 \%$ ) of the surface area of the plasma membrane. Adult segments had more SER surface area per micrometer of dendritic length $\left(1.43 \pm 0.12 \mu \mathrm{m}^{2}\right.$ per micrometer of length versus $0.83 \pm 0.26$ for $\mathrm{P} 21$ and $0.81 \pm 0.06$ for P15; HSD; $p<0.03)$.

Although most SER was located in the dendrites, it occasionally extended into dendritic spines. SER was found in the head or neck of $15 \%$ of spines at P15. Similarly, $11 \%$ of spines at P21 and $20 \%$ of spines in the adult contained SER. The spine apparatus is a prominent specialization of the SER found in large spines (Gray, 1959; Spacek, 1985; Spacek and Harris, 1997). In the reconstructed adult dendrites, five of six large mushroom spines contained SER, and in every case this was in the form of a spine apparatus. Spine apparatuses were far less frequent in younger animals. Only 1 of 24 mushroom spines at P21 contained a spine apparatus, and no spine apparatuses were found in P15 spines. Still, two of three mushroom spines contained SER at P15, and $30 \%$ of mushroom spines contained SER at P21. Thin spines contained SER much less often at 15, 7, and $11 \%$ of adult, P21, and P15 spines, respectively.

\section{Characterization of non-SER compartments}

With the SER completely identified by reconstruction, additional membranous compartments independent from SER and mitochondria were evident. Most of these compartments could also be distinguished from SER on the basis of the distinctive morphological characteristics described below. The non-SER compart-

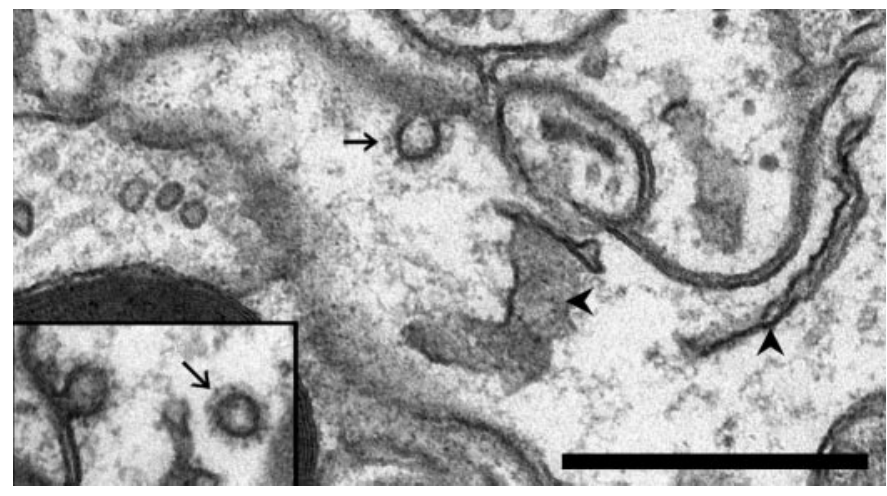

Figure 2. A coated pit (arrow) in a spine head. The synapse (not visible on this section) lies on the opposite side of the spine head. SER (arrowheads) is visible in the spine neck as a flattened sheet and in the dendrite as a thin compartment. Inset, A coated vesicle (arrow) and a coated pit in a dendrite shaft. Scale bar, $0.5 \mu \mathrm{m}$. 
Table 2. Dimensions of endosomal compartments

\begin{tabular}{|c|c|c|c|c|c|c|c|}
\hline \multirow[b]{2}{*}{ Compartment } & \multicolumn{3}{|c|}{ Diameter (nm) } & \multicolumn{3}{|c|}{ Length (nm) } & \multirow[b]{2}{*}{ Putative functional stage } \\
\hline & Min & $\operatorname{Max}$ & Mean \pm SEM & Min & $\operatorname{Max}$ & Mean \pm SEM & \\
\hline Coated pit & 50 & 100 & $76 \pm 2.7$ & 70 & 110 & $92 \pm 2.7$ & Endocytosis \\
\hline Coated vesicle & 55 & 75 & $66 \pm 2.6$ & 70 & 100 & $82 \pm 2.7$ & Endocytosis \\
\hline Large vesicle & 55 & 95 & $69 \pm 1.5$ & 70 & 120 & $83 \pm 1.7$ & Post-endocytosis \\
\hline Tubule & 37 & 75 & $47 \pm 0.5$ & 90 & 740 & $190 \pm 11$ & Recycling/sorting \\
\hline Multivesicular body & 150 & 340 & $242 \pm 10$ & & $\sim \mathrm{Sph}$ & & Carrier vesicle \\
\hline Small vesicle & 40 & 60 & $49 \pm 0.4$ & & $\sim \mathrm{Sph}$ & & Exocytosis \\
\hline
\end{tabular}

Min, Minimum; Max, maximum.
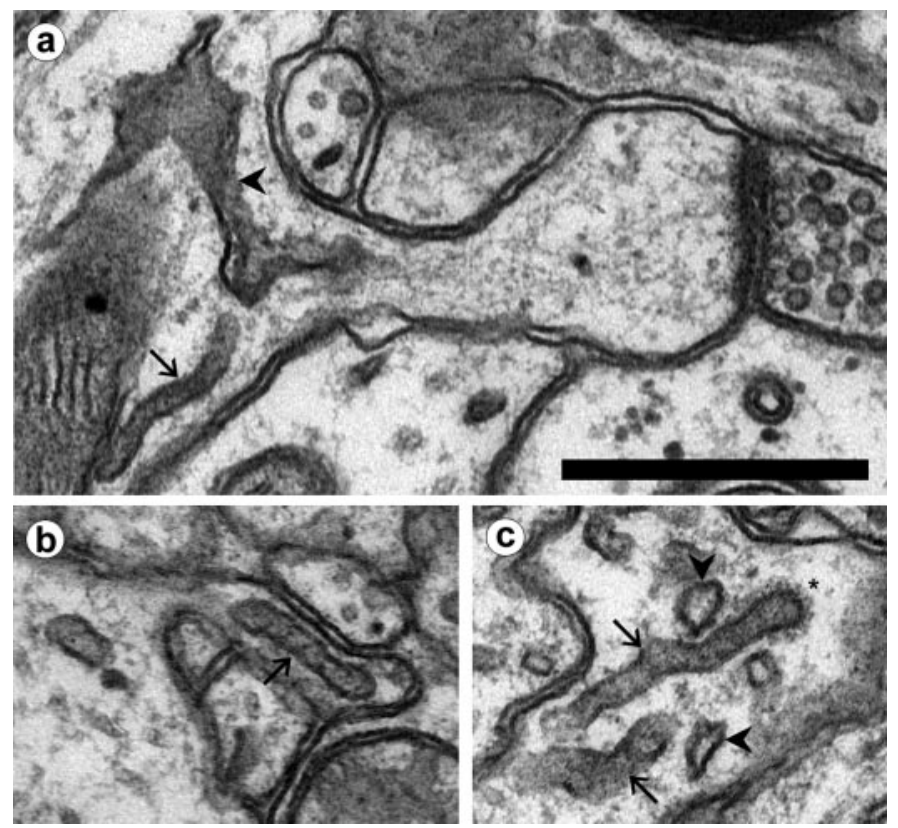

Figure 3. Tubular compartments in dendrites and spines. a, SER (arrowhead) extends into the neck of a thin spine. A non-SER tubular compartment (arrow) at the origin of the spine exhibits a uniform diameter compared with SER. $b$, A non-SER tubule (arrow) in a spine neck. $c$, A coated bud (*) at the tip of a tubule. Note the darker interior of the tubular compartments (arrows) as compared with SER (arrowheads). Scale bar, $0.5 \mu \mathrm{m}$.

ments exhibited one of four general morphologies: vesicular, tubular, multivesicular, or amorphous vesicular.

Vesicular compartments were round or ellipsoidal and included coated pits, coated vesicles, large (uncoated) vesicles, and small (uncoated) vesicles. Coated pits were included in the vesicular category because of their obvious relationship to coated vesicles (Mukherjee et al., 1997). These pits were elliptical, omega-shaped invaginations with gray interiors and cytoplasmic coats consisting of a number of spoke-like protrusions typical of clathrin (Fig. 2). Coated vesicles were also elliptical with gray interiors and clathrin coats. Large vesicles had gray interiors and a smooth outer membrane and were similar in dimensions to coated vesicles (Table 2). Given the similarity in size, large vesicles were likely produced by the dissociation of clathrin from coated vesicles after endocytosis. Small vesicles had light gray interiors and a distinctive diameter of $\sim 50 \mathrm{~nm}$.

Tubular compartments were cylindrical in shape with smooth outer membranes and dark, grainy interiors (Fig. 3). Clathrin-like protein coats occurred at the ends of some of the tubular com-
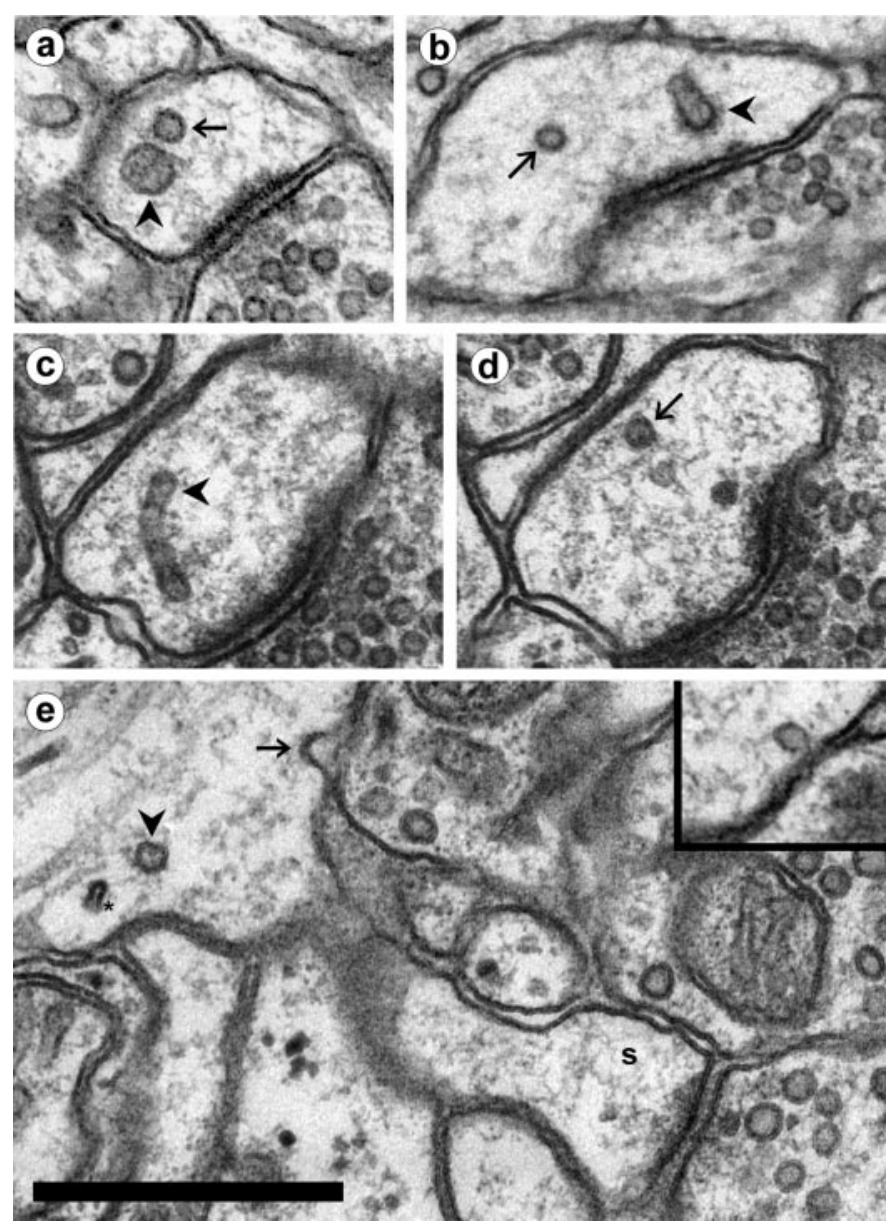

Figure 4. Small vesicles in dendrites. $a$, A large vesicle (arrowhead) next to a small vesicle (arrow) in a spine head. Note the distinctive difference in size. $b$, A small vesicle (arrow) in a spine head with a tubular compartment that has a coated tip (arrowhead). $c, d$, Adjacent serial sections showing a tubular compartment (c, arrowhead) with a small vesicle $(d$, arrow) of the same diameter near its tip. $e$, A small vesicle-sized omega figure (arrow) in the plasmalemma at the base of a thin spine $(s)$. A cross-sectioned tubular endosome (arrowhead) is also at the spine origin, near a thinner cross-section of SER (*). Inset, A small vesicle adjacent to the plasmalemma in a spine head. Scale bar, $0.5 \mu \mathrm{m}$.

partments (Fig. 3c). The presence of these coats is consistent with a process of vesicle budding from the tubules (Stoorvogel et al., 1996). The diameter of the tubules was uniform and similar to that of small vesicles (Table 2), suggesting that small vesicles arise from the tubules. Small vesicles could be found in close association with tubular compartments and were observed in continuity 

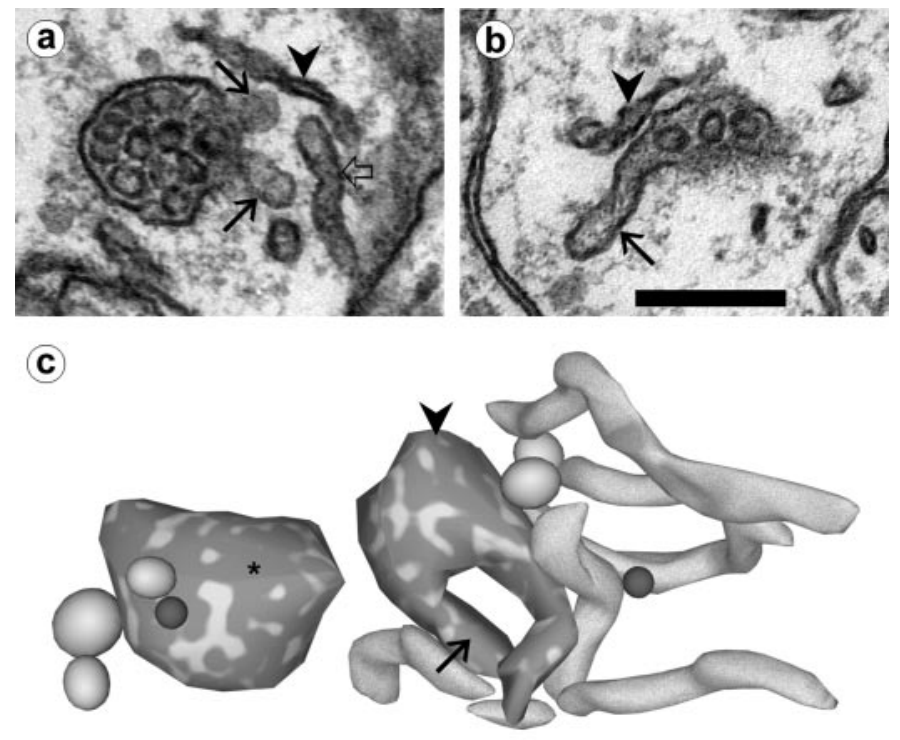

Figure 5. Multivesicular body/tubule complexes in dendrites. $a$, An MVB with attached tubules (arrows). Compare the flattened appearance of SER (arrowhead) with the more cylindrical shape of an unattached tubule (open arrow) located nearby. $b$, A tubule (arrow) is in continuity with an MVB only partially visible on this section. SER is located nearby (arrowhead). Scale bar (shown in $b$ for $a$ and $b$ ): $0.25 \mu \mathrm{m}$. $c$, Reconstruction of the MVB-tubule complex of $b$ and associated compartments. The tubule (arrow) visible in the electron micrograph is continuous with a round MVB (arrowhead) that has a second tubular extension. Several additional tubular compartments are located adjacent to this structure. An isolated MVB (*) nearby does not have any tubular extensions. Also reconstructed are several large, ellipsoidal vesicles (gray) and two spherical small vesicles (dark gray). Scale bar, $0.5 \mu \mathrm{m}$.

with the plasma membrane in dendrite shafts and spines (Fig. 4). The sizes of the vesicular and tubular compartments did not differ with age.

The largest and most conspicuous of the non-SER compartments were MVBs. MVBs had a dark, grainy interior that contained a variable number of internal vesicles. Although MVBs were sometimes found in isolation, they were more often surrounded by and connected with multiple tubular compartments (Fig. 5). Coated vesicles, large vesicles, and small vesicles were often found in the vicinity of these MVB-tubule complexes. The tubules in continuity with MVBs were morphologically similar to isolated tubular compartments and also exhibited coated tips, suggesting that they were involved in the production of small vesicles. The MVB-tubule complexes ranged in volume from 0.003 to $0.027 \mu \mathrm{m}^{3}$ (mean: $0.011 \pm 0.002 \mu \mathrm{m}^{3}$ ). The external surface of the complexes (exclusive of any internal vesicles) averaged $0.39 \pm 0.05 \mu \mathrm{m}^{2}$. The total number of internal vesicles in the MVBs ranged from 2 to 77 (mean: $24 \pm 4$ ) and was correlated with the total volume of the MVB $(r=0.85)$. There were no statistically significant differences in the volumes or surface areas of MVB-tubule complexes between ages.

The remaining non-SER compartments found in the dendrites were mitochondria and amorphous vesicles. Mitochondria occurred in the central part of the dendrite shaft, surrounded by the SER network (Fig. 1a). Amorphous vesicles had smooth membranes, electron-lucent interiors, and irregular shapes that were neither round nor ellipsoidal. The amorphous vesicular compartments were generally isolated vesicles but also occurred in clumps
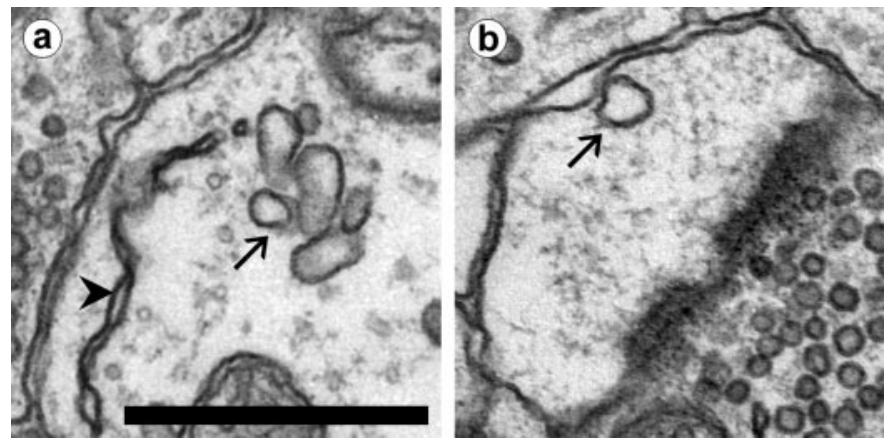

Figure 6. Amorphous vesicular compartments found in dendrites and spines. $a$, A clump of amorphous vesicles (arrow), with unattached SER nearby (arrowhead). $b$, An amorphous vesicle (arrow) adjacent to the plasma membrane in a spine head. Amorphous vesicles were in the head or neck of $5 \%$ of the spines examined in the study. Scale bar, $0.5 \mu \mathrm{m}$.

(Fig. 6). Both the isolated vesicles and clumps were found in the dendrite shaft as well as in dendritic spines, often near the plasma membrane (Fig. 6b). No large, electron-opaque bodies characteristic of lysosomes occurred in the dendritic segments that were analyzed.

\section{Identification of endosomal compartments}

The morphological characteristics of non-SER compartments are consistent with a functional interpretation in the endosomal pathway (Table 2). To verify the endosomal nature of the nonSER compartments, we examined an additional slice incubated with 3-4 nm gold-BSA. Gold particles lined the membranes in the extracellular spaces (Fig. 7). We analyzed three dendritic segments (total length: $12.2 \mu \mathrm{m}$ ) in this material using the same technique of first tracing the SER and then identifying the nonSER compartments. This analysis revealed that gold particles were taken up from the extracellular space into coated pits and dispersed among endosomal compartments. Gold was found in coated pits, coated vesicles, large vesicles, and tubular compartments (Fig. 7). Gold accumulated in the lumen of the MVBs associated with MVB-tubule complexes but not within the internal vesicles of the MVBs. The interior of these internal MVB vesicles appeared to arise from the cytoplasm rather than from the extracellular space (Fig. $7 b$ ).

The presence of gold particles in coated vesicles, large vesicles, tubular compartments, and MVB-tubule complexes indicated that they were all endosomal in origin. Gold was rarely found in small vesicles, consistent with these vesicles not arising from endocytosis. Gold was also found in amorphous vesicle clumps but not in SER (Fig. 7), suggesting that amorphous vesicles arose from plasma membrane invagination rather than from the SER.

\section{Distribution of non-SER compartments}

The frequency of non-SER compartments along the dendritic segments that were analyzed was highly variable. Differences between ages could not be detected, so all ages are grouped together for the overall frequencies of occurrence (Fig. 8). Although spines occurred at a frequency of $15-35$ per $10 \mu \mathrm{m}$ of dendrite length, even the most frequent of non-SER compartments was found at $<10$ per $10 \mu \mathrm{m}$ on average. The membrane surface area contained within the endosomal compartments was $-3.7 \%$ of the surface area of the plasma membrane of the dendrites. Small vesicle surface area was $0.3 \%$ of the plasmalemmal surface area. Three-dimensional reconstructions illustrate 
Figure 7. Gold particles conjugated with BSA were taken in from the extracellular space into endosomal compartments. $a$, Gold is seen in a coated vesicle (arrow) but not in SER (arrowhead) or a small vesicle (*) in a mushroom spine. Scale bar, $0.5 \mu \mathrm{m} . b$, Gold is seen in the lumen of an MVB in a dendrite. The MVB exhibits an invagination (arrow) that may indicate the formation of an internal vesicle. $c$, Gold is concentrated in the base of a tubular extension (arrow) from an MVB. $d$, Gold particles were found in coated pits (arrow) and in tubular compartments with coated tips (arrowhead). e, An amorphous vesicle clump with gold visible in three of the vesicles (arrows). $f$, Serial section analysis of dendrites detected gold in endocytotic vesicles ( $c p$, coated pits; $c v$, coated vesicles; $l v$, large vesicles) and non-SER tubular compartments. Gold was concentrated in MVB-tubule sorting complexes ( $c p l x)$ and mostly absent from small vesicles $(s v)$. No gold was found in any of the 1031 profiles of SER in the dendrites.
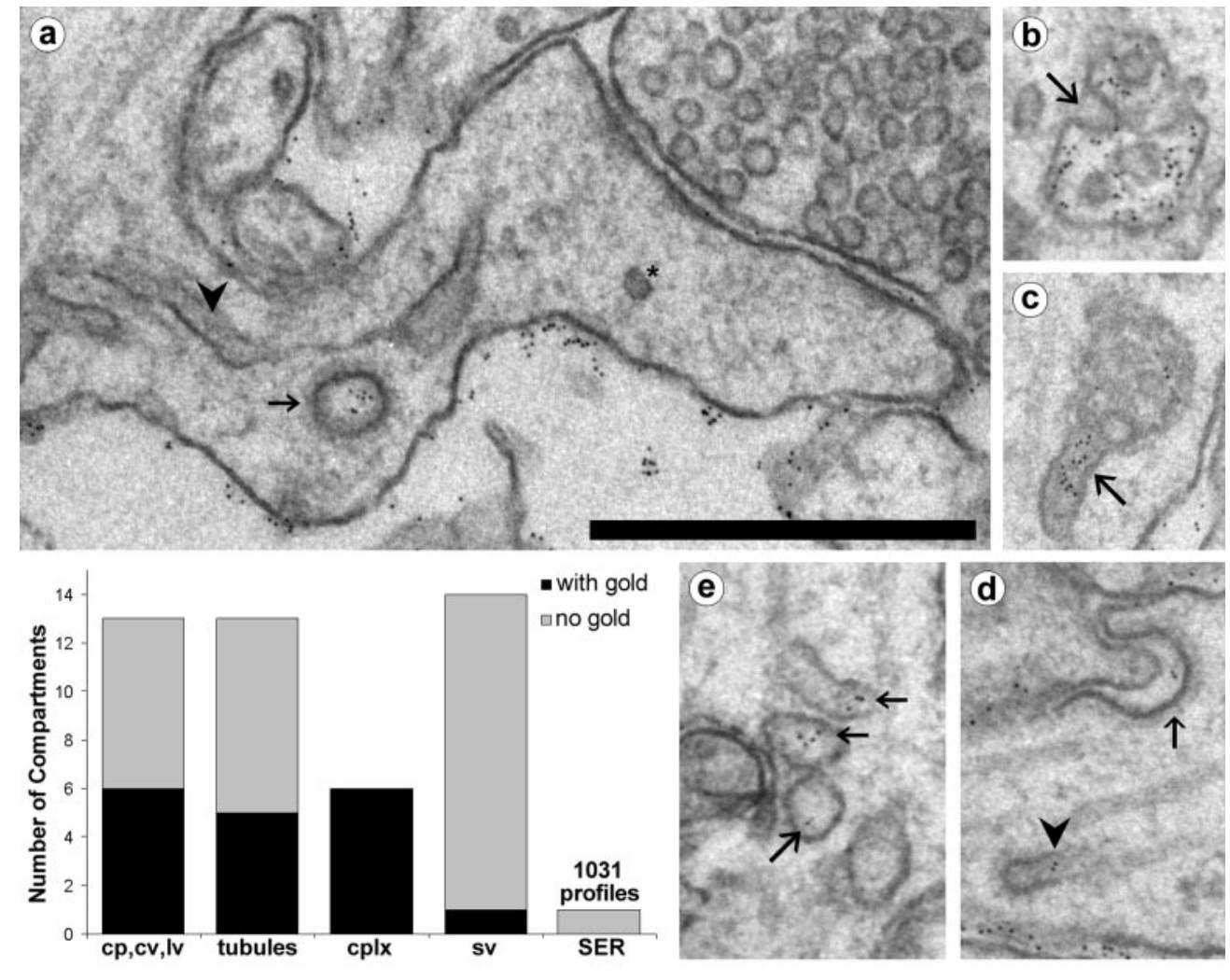

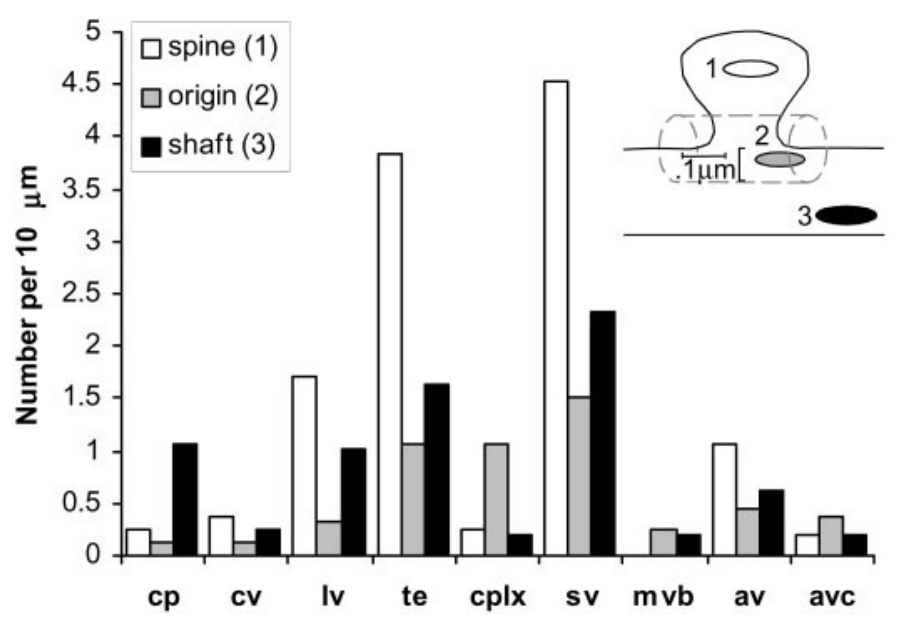

Figure 8. The frequency of each type of non-SER compartment ( $c p$, coated pits; $c v$, coated vesicles; $l v$, large vesicles; te, tubular endosomes; $c p l x$, MVB-tubule complexes; $s v$, small vesicles; $a v$, amorphous vesicles; $a v c$, amorphous vesicular clumps) in dendrites. The location of the compartment was determined to be in spines (1: in a spine head or neck), at the base of the spine (2), or in the shaft of the dendrite (3), as shown in the inset.

the rather sparse distribution of non-SER compartments in representative dendrites (Fig. 9).

Clathrin-coated pits and vesicles were found primarily in the dendrite shaft (Fig. 8). Coated pits and vesicles were occasionally found in spines, especially in the larger spines of adult dendrites (Fig. 2). To examine the frequency of endocytosis in more adult spines, a section-by-section analysis of the distribution of clathrincoated structures was performed on one adult series. This volume of 89 sections (each $48 \mu \mathrm{m}^{2}$ by $55 \mathrm{~nm}$ thick) contained hundreds of dendritic spine synapses. A total of 88 clathrin-coated structures were unambiguously identified in this volume. A substantial portion of these coats (17) occurred at the ends of tubular compartments. Of coated pits and vesicles, only 6 of 88 were found in the heads or necks of dendritic spines, whereas 26 occurred in dendrite shafts and 29 were found in axonal and other processes.

Large vesicles were more frequent than coated pits $(1.6 / 10 \mu \mathrm{m})$ and coated vesicles $(0.9 / 10 \mu \mathrm{m})$ combined, occurring at a rate of 3.0/10 $\mu \mathrm{m}$. Large vesicles were often found in spines (Fig. 8). Small vesicles were the most abundant non-SER compartments in dendrites $(8.6 / 10 \mu \mathrm{m})$ and were found predominantly in spines. Tubular endosomes were also commonly found in spines, with an overall frequency of occurrence of $6.6 / 10 \mu \mathrm{m}$. Isolated MVBs were rare $(0.4 / 10 \mu \mathrm{m})$, whereas MVB-tubule complexes occurred more frequently $(1.5 / 10 \mu \mathrm{m})$. The largest portion of the endosomal volume was found at spine origins because of the occurrence of large MVB-tubule complexes there (Fig. 10).

\section{Endosomal compartments in spines}

Approximately $70 \%$ of the non-SER compartments were located within or at the base of dendritic spines (Fig. 8). At least three functionally distinct types of membranous organelles were found in spines: SER, endosomes, and small vesicles. To assess the relative frequency of these organelles, spines were classified as containing SER, endosomes, or small vesicles as follows. Spines contained SER when one or more cisternae of SER or a spine apparatus extended into the neck or head. Spines contained endosomal compartments when one or more coated pits, coated vesicles, large vesicles, tubular compartments, MVBs, or MVBtubule complexes were observed in the spine head or neck or at the spine origin (Fig. 8, inset). Similarly, spines were considered to contain small vesicles when they were found in the head or neck or at the origin. At all ages, approximately half the spines did not 


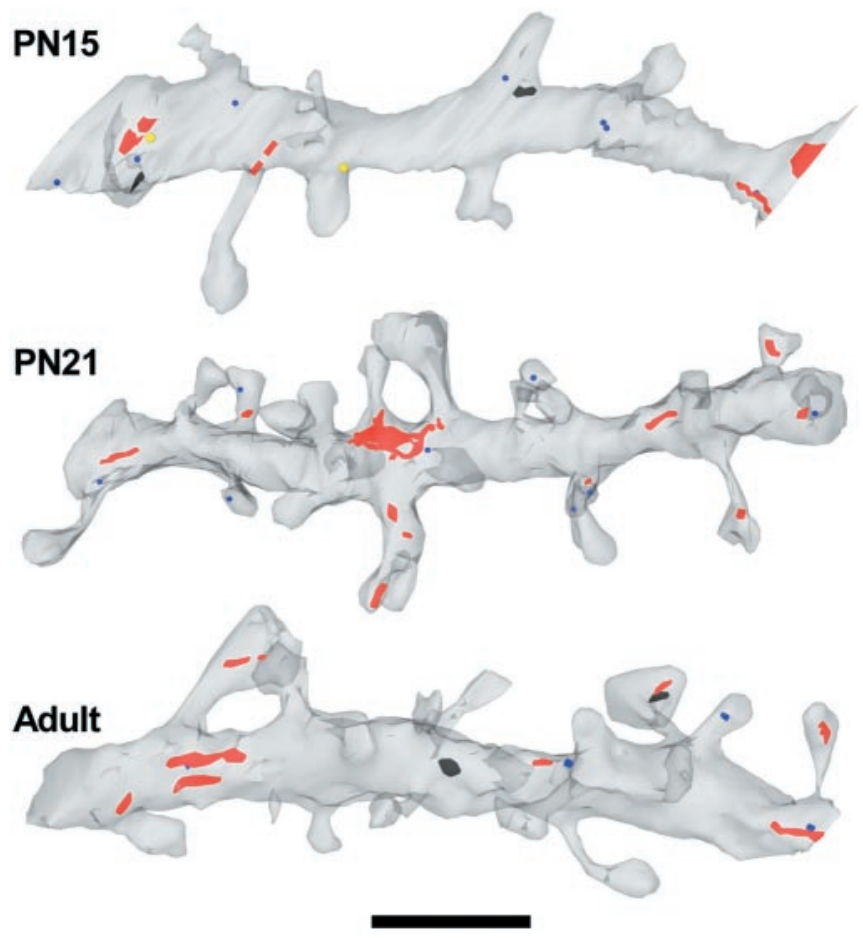

Figure 9. Three-dimensional reconstructions of representative dendritic segments from each age. Endocytotic vesicles (coated pits, coated vesicles, and large vesicles) are shown in yellow. Tubular endosomes, MVBs, and MVB-tubule sorting complexes are red. These structures are infrequent along the length of the dendrites relative to the frequency of spines. Small vesicles (blue) are often located in spines but only occasionally colocalize with endosomes. Amorphous vesicles are shown in dark brown. Scale bar, $1 \mu \mathrm{m}$.

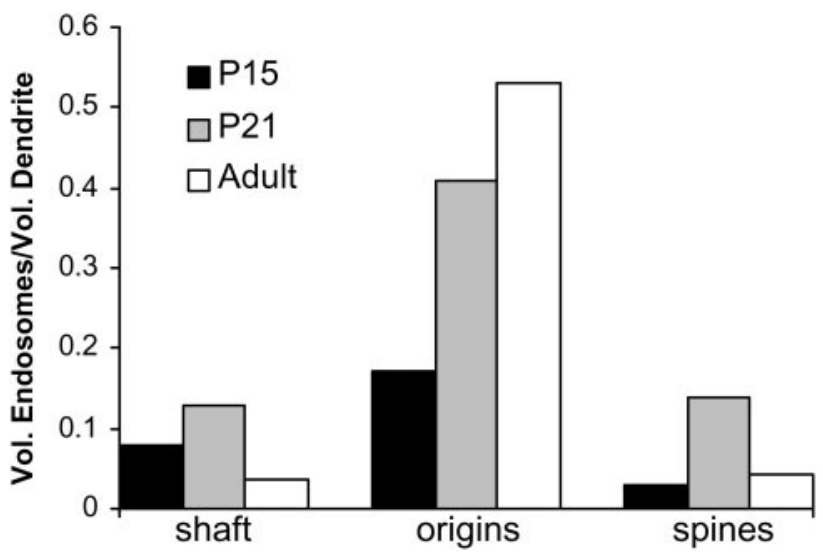

Figure 10. Distribution of endosomal volume. More endosomal compartments are found in spines than at spine origins; however, the bulk of endosomal volume is found in MVBs and sorting complexes, which are localized primarily at spine origins.

contain any of these three compartment types (Fig. 11). Similar proportions of spines contained only SER, endosomes, or small vesicles at the three ages $\left(\chi^{2} ; p=0.34\right)$. Also, the proportion of spines containing each of the three types of compartments did not differ between ages $\left(\chi^{2}\right.$; SER, $p=0.25$; endosomal, $p=0.52$; small vesicles, $p=0.09)$.

Because the distribution of SER, endosomal, and small vesicle compartments was similar for all three ages, the data from all ages
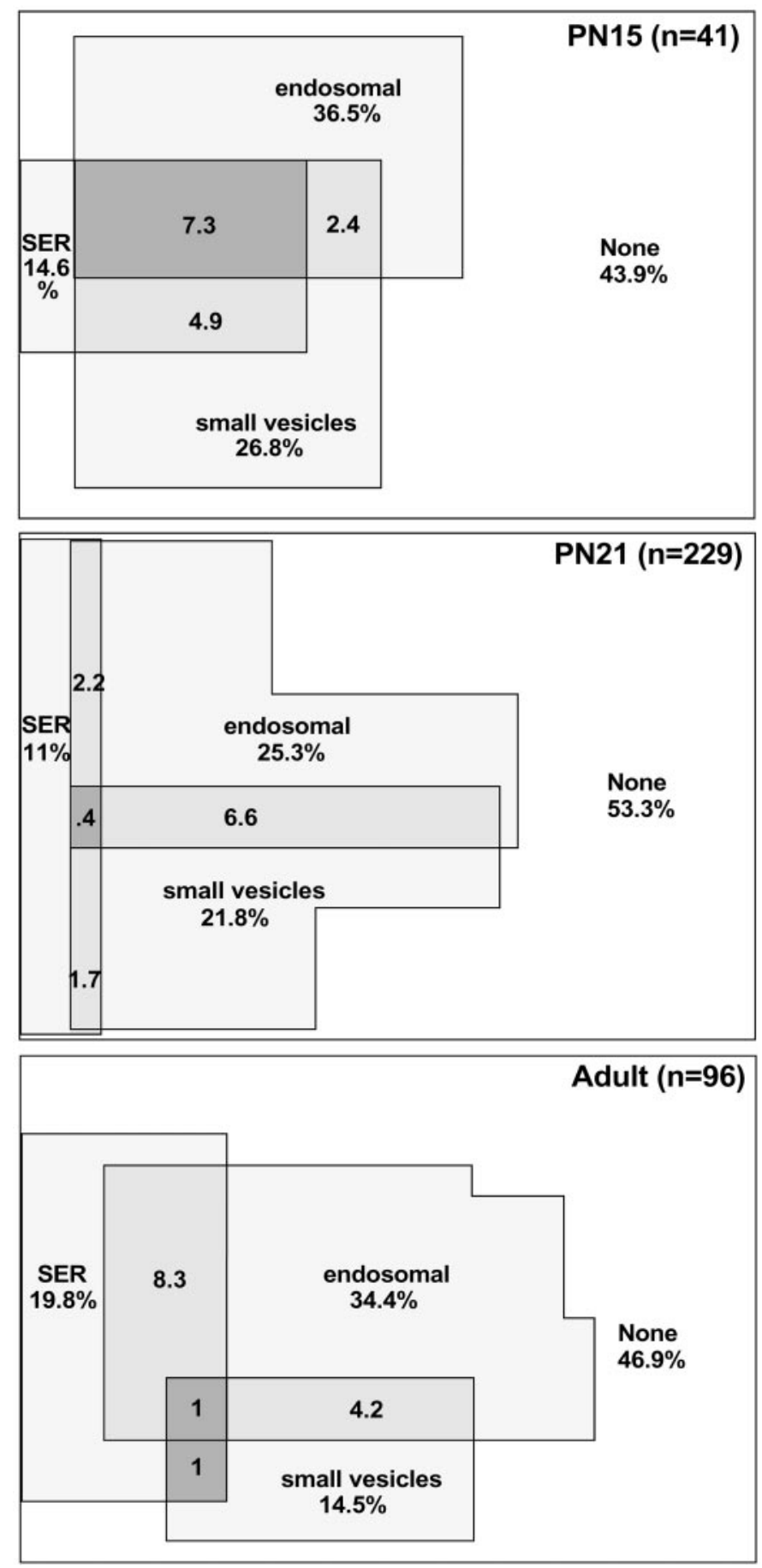

Figure 11. Venn diagrams showing the percentage of spines that contained SER, an endosomal compartment (coated pit, coated vesicle, large vesicle, tubular endosome, or MVB-tubule complex), or small vesicles at each age. The overlap areas show the percentages of spines with more than one type of compartment. The percentages under the labels give the overall proportion of spines containing a particular type of compartment. Thus, $19.8 \%$ of adult spines contained SER, whereas $1 \%$ of adult spines contained SER, endosomes, and small vesicles.

were combined for an overall analysis of organelle distribution. Approximately $49 \%$ of dendritic spines contained one of the three compartments. SER extended into $14 \%$ of spines. Endosomal compartments were found in the head or neck of $18 \%$ of spines and were found at the origin of an additional $11 \%$ of 


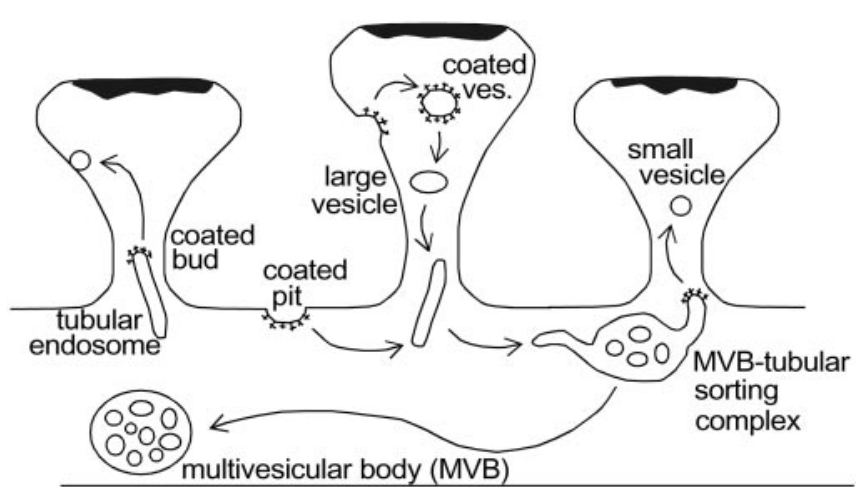

Figure 12. Diagram of the putative itinerary of endosomal compartments in distal dendrites. Clathrin-coated pits invaginate to form coated vesicles that become large vesicles after the loss of the coat. Large vesicles merge into tubular endosomes and MVB-tubular complexes. Sorted, soma-bound material leaves the dendrite via isolated MVBs. The coated tips of tubular endosomes give rise to small, round vesicles that return to fuse with the plasmalemma. The source and target regions of the plasmalemma for these components are likely to be disparate.

spines. Small vesicles, representing potential exosomes, were present in $20 \%$ of spines overall. Curiously, occurrences of both endosomes and small vesicles together in spines were relatively rare (Fig. 11). To test whether the co-occurrences of the three compartment types were random events, the proportions of expected co-occurrences by chance given the frequency of each type were compared with the actual proportions. These distributions were not significantly different $\left(\chi^{2} ; p=0.44\right)$. Only $1.4 \%$ of spines contained all three compartments. Thus, SER, endosomes, and small vesicles appear to localize to spines independently of one another.

Large spines might be expected to contain a larger complement of compartment types because of their larger overall volumes and synapse sizes. Thus, the distribution of SER, endosomes, and small vesicles was compared in mushroom versus thin spines and found to be significantly different $\left(\chi^{2} ; p<0.0002\right)$. A larger proportion of mushroom spines contained SER (45\%), endosomes $(58 \%)$, and small vesicles (24\%). Although $54 \%$ of thin spines did not contain any of the three compartments, $88 \%$ of mushrooms contained at least one of them. Endosomes and SER occurred together more frequently in mushroom spines (18 vs $1.7 \%$ in thin spines), as did endosomes and small vesicles (12 vs $3.8 \%$ in thin spines). Occurrences of SER and small vesicles together were rare in both types of spines (mushrooms: $3 \%$; thins: $1.3 \%$ ), much less than would be expected by chance. Of the mushroom spines that contained a spine apparatus, only half of them also had endosomes, and none had small vesicles.

\section{DISCUSSION}

These findings are the first to distinguish endosomes from SER in assessing their three-dimensional distribution in dendrites and spines. The three-dimensional reconstructions confirm that the SER is a continuous reticulum in distal dendrites (Martone et al., 1993; Krijnse-Locker et al., 1995; Spacek and Harris, 1997). The SER in these dendrites undergoes a maturation process after P21 that results in an increased amount of SER along the length of the dendrite and development of spine apparatuses. This process occurs after the development of spines, because adult and P21 dendrites were equally spiny, but P21 dendrites were more similar to P15 dendrites in terms of the distribution of SER. The SER network extended into only $14 \%$ of reconstructed spines across all three ages. This is consistent with reports of calcium precipitates labeling $13-16 \%$ of spines in hippocampal cultures (Buchs and Muller, 1996; Toni et al., 1999). Calcium precipitates localize postsynaptically within SER, mitochondria, and MVBs (Fifková et al., 1983; Buchs et al., 1994). Because spines rarely contain mitochondria or MVBs, only spines with SER are labeled with precipitate.

These findings also establish that components of the endocytotic, sorting, and recycling pathways can be distinguished in neuronal dendrites using morphological criteria (Fig. 12). The initial step, clathrin-mediated endocytosis, is evident as coated pits and vesicles. This was confirmed by the uptake of extracellular particles, as shown previously (Rosenbluth and Wissig, 1964; Waxman and Pappas, 1969). Endocytosed vesicles were identifiable after uncoating as large vesicles with the same size and contents as coated vesicles. Spine heads did not appear to be a preferred location of endocytosis because less than half of these endocytotic components (coated pits, coated vesicles, and large vesicles) were found in spines, whereas half of the dendritic surface area was devoted to spines in the adult.

Internalized vesicles merge into either tubular compartments or MVB-tubule complexes, from which material is recycled locally to the plasmalemma or sent to the somatic region for bulk sorting or degradation (van Deurs et al., 1995; Futter et al., 1996; Mukherjee et al., 1997; Prekeris et al., 1998, 1999). The formation of tubular endosomes from internalized vesicles is consistent with the observation that gold-BSA particles occurred in isolated tubules even though they will ultimately follow the degradative pathway. Thus, these tubules did not originate from MVB-tubule complexes in which gold-BSA was already sorted. Endocytosis into endosomal tubules before sorting is consistent with observations in other cell types (Stoorvogel et al., 1996; Morales et al., 1999). In the dendrites that we analyzed, the endosomal tubules were relatively short, discrete entities rather than part of an interconnected network as observed previously in cultured neurons (Parton et al., 1992). These isolated endosomal tubules were found frequently in spine heads. Because coated tips were found on these tubules in spines, they appeared to be involved in local recycling near the synapse. The possibility remains, however, that the tubules originated from MVB-tubule complexes and migrated into spines rather than forming in spines de novo.

MVB-tubule complexes appear to correspond to the sorting endosomes involved in separating soma-bound material from recyclable material (Geuze et al., 1983; Mellman, 1996; Mukherjee et al., 1997). The three-dimensional structure of the sorting endosomes in dendrites was consistent with that observed in kidney cells (Marsh et al., 1986). These structures were localized to hippocampal spine origins, as noted previously for visual cortex (Spacek, 1985). Sorting endosomes were occasionally found within spines, and previous observations of MVBs in spines in fact may have been sorting endosomes (Spacek and Harris, 1997). The frequency of MVB-tubule complexes $(1.5 / 10 \mu \mathrm{m})$ suggests that there is only one sorting endosome per 20 spines in P21 and older dendrites. Because receptor recycling is known to be activity dependent (Ehlers, 2000), the low incidence of sorting endosomes may be attributable to a relatively low rate of recycling activity in the anesthetized brain and hippocampal slice preparations that were studied. Still, MVB-tubule complexes were more numerous in our dendrites than glutamate receptor-labeled endosomes observed in activated neuronal cultures by fluorescent light microscopy (Snyder et al., 2001).

MVBs without attached tubules carry sorted material to the 
soma (Parton et al., 1992; Futter et al., 1996; Mukherjee et al., 1997). Isolated MVBs were infrequent in distal dendrites and did not appear in spines, nor were they preferentially located at spine origins. In addition, no lysosome-like structures were found in the distal dendrites, consistent with immunofluorescence studies (Parton et al., 1992).

In addition to the large ellipsoid vesicles mentioned above, we identified numerous smaller round vesicles $\sim 50 \mathrm{~nm}$ in diameter, often in spines. Separate classes of large and small vesicles are consistent with the endocytotic and exocytotic vesicles distinguished by immunocytochemistry in other cell types (Stoorvogel et al., 1996). Small vesicles in neuronal dendrites could originate from tubular compartments, which are also $50 \mathrm{~nm}$ in diameter, by a process of clathrin-mediated budding, as expected for the return pathway from endosomes to the plasma membrane (Stoorvogel et al., 1996; Mukherjee et al., 1997). Small (50 nm) omega figures were observed at the plasma membrane (Fig. 4) (Spacek and Harris, 1997), but small vesicles rarely contained extracellular gold, suggesting that they are exosomal rather than endosomal.

Proposals for the source of new synaptic receptors in dendrites have included endosomal compartments (Ehlers, 2000; Lin et al., 2000; Carroll et al., 2001; Lüscher and Frerking, 2001; Sheng and Lee, 2001), SER and the spine apparatus (Tarrant and Routtenberg, 1979; Westrum et al., 1980; Nusser et al., 1998; Rubio and Wenthold, 1999; Shi et al., 1999), and trans-Golgi compartments (Maletic-Savatic and Malinow 1998; Pierce et al., 2000, 2001). Receptor insertion from SER would presumably rely on vesicular transport, because LTP is dependent on vesicular exocytosis (Lledo et al., 1998; Lüscher et al., 1999). However, no coated vesicle budding was observed from the spine apparatus or other regions of the SER. The possibility that non-coated vesicle budding occurs from SER also seems unlikely, because small exocytotic vesicles did not colocalize with SER in spines. Although it is possible that the amorphous vesicles might be a mechanism of vesicular transport of receptors, they were often found in clumps near the plasma membrane and contained gold particles, suggesting that they are probably caveoli or pinocytotic vesicles (Roizin et al., 1967). It is also possible that amorphous vesicles were fixation artifacts, because some forms of fixation are known to produce similar vesicular invaginations (Rosenbluth, 1963; Doggenweiler and Heuser, 1967; Silva et al., 1976; Hasty and Hay, 1978). In any case, vesicular insertion from SER or the spine apparatus was not evident in the present study. Further investigation is needed to determine whether non-vesicular receptor insertion might serve as an alternative pathway for receptors from the SER (Rubio and Wenthold, 1999).

In considering endosomes as the most likely source of synaptic receptors, it is remarkable that exocytotic small vesicles are not strongly colocalized with endosomal compartments in spines. In light of the relatively low frequency of endosomes along the dendrites, this suggests that individual spines do not have local, stabilized endosomal compartments involved in constitutive receptor recycling. A model more compatible with the disparate localization of endosomal and exocytotic components is that receptors are recycled among a pool of synapses along the length of the dendrite. The ratio of spine density to endosome density gives an indication of the size of the synapse pool involved in recycling. If all recycling passes through sorting complexes, then $\sim 20$ synapses are pooled in adult and P21, whereas 13 synapses are pooled at P15. If the more frequently encountered tubular compartments also recycle independently, then the synapse pool drops to two to four synapses for all ages. In any case, the rapid
$(<5$ min) receptor insertion at a synapse that accompanies LTP may rely on receptors gleaned from a pool of neighboring synapses. This mechanism may contribute to the depression of neighboring synapses after LTP (Lynch et al., 1977; Huerta and Lisman, 1995; Coussens and Teyler, 1996; Bi and Poo, 2001).

\section{REFERENCES}

Bi G, Poo M (2001) Synaptic modification by correlated activity: Hebb's postulate revisited. Annu Rev Neurosci 24:139-166.

Buchs PA, Muller D (1996) Induction of long-term potentiation is associated with major ultrastructural changes of activated synapses. Proc Natl Acad Sci USA 93:8040-8045.

Buchs PA, Stoppini L, Párducz A, Siklós L, Muller D (1994) A new cytochemical method for the ultrastructural localization of calcium in the central nervous system. J Neurosci Methods 54:83-93.

Carroll RC, Beattie EC, Xia H, Lüscher C, Altschuler Y, Nicoll RA, Malenka RC, von Zastrow M (1999) Dynamin-dependent endocytosis of ionotropic glutamate receptors. Proc Natl Acad Sci USA 96:14112-14117.

Carroll RC, Beattie EC, von Zastrow M, Malenka RC (2001) Role of AMPA receptor endocytosis in synaptic plasticity. Nat Rev Neurosci 2:315-324.

Coussens CM, Teyler TJ (1996) Long-term potentiation induces synaptic plasticity at nontetanized adjacent synapses. Learn Mem 3:106-114.

Doggenweiler CF, Heuser JE (1967) Ultrastructure of the prawn nerve sheaths. Role of fixative and osmotic pressure in vesiculation of thin cytoplasmic laminae. J Cell Biol 34:407-420.

Ehlers MD (2000) Reinsertion or degradation of AMPA receptors determined by activity-dependent endocytic sorting. Neuron 28:511-525.

Feinberg MD, Szumowski KM, Harris KM (2001) Microwave fixation of rat hippocampal slices. In: Microwave techniques and protocols (Giberson RT, Demaree RS, eds), pp 75-88. Totowa, NJ: Humana.

Fiala JC, Harris KM (2001a) Extending unbiased stereology of brain ultrastructure to three-dimensional volumes. J Am Med Inform Assoc $8: 1-16$.

Fiala JC, Harris KM (2001b) Cylindrical diameters method for calibrating section thickness in serial electron microscopy. J Microsc 202:468-472.

Fifková E, Markham JA, Delay RJ (1983) Calcium in the spine apparatus of dendritic spines in the dentate molecular layer. Brain Res 266:163-168.

Futter CE, Pearse A, Hewlett LJ, Hopkins CR (1996) Multivesicular endosomes containing internalized EGF-EGF receptor complexes mature and then fuse directly with lysosomes. J Cell Biol 132:1011-1023.

Geuze HJ, Slot JW, Strous GJAM, Lodish HF, Schwartz AL (1983) Intracellular site of asialoglycoprotein receptor-ligand uncoupling: double-label immunoelectron microscopy during receptor-mediated endocytosis. Cell 32:277-287.

Gray EG (1959) Axo-somatic and axo-dendritic synapses of the cerebral cortex: an electron microscope study. J Anat 97:420-433.

Harris KM, Stevens JK (1989) Dendritic spines of CA1 pyramidal cells in the rat hippocampus: serial electron microscopy with reference to their biophysical characteristics. J Neurosci 9:2982-2997.

Harris KM, Jensen FE, Tsao B (1992) Three-dimensional structure of dendritic spines and synapses in rat hippocampus (CA1) at postnatal day 15 and adult ages: implications for the maturation of synaptic physiology and long-term potentiation. J Neurosci 12:2685-2705.

Hasty DL, Hay ED (1978) Freeze-fracture studies of the developing cell surface. II. Particle-free membrane blisters on glutaraldehyde-fixed corneal fibroblasts are artifacts. J Cell Biol 78:756-768.

Hayashi Y, Shi SH, Esteban JA, Piccini A, Poncer JC, Malinow R (2000) Driving AMPA Receptors into Synapses by LTP and CaMKII: requirement for GluR1 and PDZ domain interaction. Science 287:2262-2267.

Huerta PT, Lisman JE (1995) Bidirectional synaptic plasticity induced by a single burst during cholinergic theta oscillation in CA1 in vitro. Neuron 15:1053-1063.

Jensen FE, Harris KM (1989) Preservation of neuronal ultrastructure in hippocampal slices using rapid microwave-enhanced fixation. J Neurosci Methods 29:217-230.

Kirov SA, Sorra KE, Harris KM (1999) Slices have more synapses than perfusion-fixed hippocampus from both young and mature rats. J Neurosci 19:2876-2886.

Krijnse-Locker J, Parton RG, Fuller SD, Griffiths G, Dotti CG (1995) The organization of the endoplasmic reticulum and the intermediate compartment in cultured rat hippocampal neurons. Mol Biol Cell 6:1315-1332.

Lin JW, Ju W, Foster K, Lee SH, Ahmadian G, Wyszynski M, Wang YT, Sheng M (2000) Distinct molecular mechanisms and divergent endocytotic pathways of AMPA receptor internalization. Nat Neurosci 3:1282-1290.

Lledo PM, Zhang X, Südhof TC, Malenka RC, Nicoll RA (1998) 
Postsynaptic membrane fusion and long-term potentiation. Science 279:399-403.

Lüscher C, Frerking M (2001) Restless AMPA receptors: implications for synaptic transmission and plasticity. Trends Neurosci 24:665-670.

Lüscher C, Houhui X, Beattie EC, Carroll RC, von Zastrow M, Malenka RC, Nicoll RA (1999) Role of AMPA receptor cycling in synaptic transmission and plasticity. Neuron 24:649-658.

Lynch GS, Dunwiddle T, Gribkoff V (1977) Heterosynaptic depression: a postsynaptic correlate of long-term potentiation. Nature 266:737-739.

Maletic-Savatic M, Malinow R (1998) Calcium-evoked dendritic exocytosis in cultured hippocampal neurons. Part I: trans-Golgi networkderived organelles undergo regulated exocytosis. J Neurosci 18:6803-6813.

Man HY, Lin JW, Ju WH, Ahmadian G, Liu L, Becker LE, Sheng M, Wang YT (2000) Regulation of AMPA receptor-mediated synaptic transmission by clathrin-dependent receptor internalization. Neuron 25:649-662.

Marsh M, Griffiths G, Dean GE, Mellman I, Helenius A (1986) Threedimensional structure of endosomes in BHK-21 cells. Proc Natl Acad Sci USA 83:2899-2903.

Martone ME, Zhang Y, Simpliciano VM, Carragher BO, Ellisman MH (1993) Three-dimensional visualization of the smooth endoplasmic reticulum in Purkinje cell dendrites. J Neurosci 13:4636-4646.

Mellman I (1996) Endocytosis and molecular sorting. Annu Rev Cell Dev Biol 12:575-625.

Morales CR, Zhao Q, Lefrancois S (1999) Biogenesis of lysosomes by endocytic flow of plasma membrane. Biocell 23:149-160.

Mukherjee S, Ghosh RN, Maxfield FR (1997) Endocytosis. Physiol Rev 77:759-803.

Nusser Z, Lujan R, Laube G, Roberts JDB, Molnar E, Somogyi P (1998) Cell type and pathway dependence of synaptic AMPA receptor number and variability in the hippocampus. Neuron 21:545-559.

Parton RG, Simons K, Dotti CG (1992) Axonal and dendritic endocytotic pathways in cultured neurons. J Cell Biol 119:123-137.

Pierce JP, van Leyen K, McCarthy JB (2000) Translocation machinery for synthesis of integral membrane and secretory proteins in dendritic spines. Nat Neurosci 3:311-313.

Pierce JP, Mayer T, McCarthy JB (2001) Evidence for a satellite secretory pathway in neuronal dendritic spines. Curr Biol 11:351-355.

Prekeris R, Klumperman J, Chen YA, Scheller RH (1998) Syntaxin 13 mediates cycling of plasma membrane proteins via tubulovesicular recycling endosomes. J Cell Biol 143:957-971.

Prekeris R, Foletti DL, Scheller RH (1999) Dynamics of tubulovesicular recycling endosomes in hippocampal neurons. J Neurosci 19:1032410337.

Roizin L, Nishikawa K, Koizumi J, Keoseian S (1967) The fine structure of the multivesicular body and their relationship to the ultracellular constituents of the central nervous system. J Neuropathol Exp Neurol 26:223-249.

Rosenbluth J (1963) Contrast between osmium-fixed and permanganatefixed toad spinal ganglia. J Cell Biol 16:143-157.

Rosenbluth J, Wissig SL (1964) The distribution of exogenous ferritin in toad spinal ganglia and the mechanism of its uptake by neurons. J Cell Biol 23:307-325.

Rubio ME, Wenthold RJ (1999) Differential distribution of intracellular glutamate receptors in dendrites. J Neurosci 19:5549-5562.

Sheng M, Lee SH (2001) AMPA receptor trafficking, the control of synaptic transmission. Cell 105:825-828.

Shi SH, Hayashi Y, Petralia RS, Zaman SH, Wenthold RJ, Svoboda K, Malinow R (1999) Rapid spine delivery and redistribution of AMPA receptors after synaptic NMDA receptor activation. Science 284:1811-1816.

Silva MT, Sousa JCF, Polónia JJ, Macedo MAE, Parente AM (1976) Bacterial mesosomes. Real structures or artifacts? Biochim Biophys Acta 443:92-105.

Slot JW, Geuze HJ (1985) A new method of preparing gold probes for multiple-labeling cytochemistry. Eur J Cell Biol 38:87-93.

Snyder EM, Philpot BD, Huber KM, Dong X, Fallon JR, Bear MF (2001) Internalization of ionotropic glutamate receptors in response to mGluR activation. Nat Neurosci 4:1079-1085.

Spacek J (1985) Three-dimensional analysis of dendritic spines II. Spine apparatus and other cytoplasmic components. Anat Embryol 171:235-243.

Spacek J, Harris KM (1997) Three-dimensional organization of smooth endoplasmic reticulum in hippocampal CA1 dendrites and dendritic spines of the immature and mature rat. J Neurosci 17:190-203.

Spacek J, Lieberman AR (1980) Relationships between mitochondrial outer membranes and agranular reticulum in nervous tissue: ultrastructural observations and a new interpretation. J Cell Sci 46:129-147.

Stoorvogel W, Oorschot V, Geuze HJ (1996) A novel class of clathrincoated vesicles budding from endosomes. J Cell Biol 132:21-33.

Tarrant SB, Routtenberg A (1979) Postsynaptic membrane and spine apparatus: proximity in dendritic spines. Neurosci Lett 11:289-294.

Toni N, Buchs PA, Nikonenko I, Bron CR, Muller D (1999) LTP promotes formation of multiple spine synapses between a single axon terminal and a dendrite. Nature 402:421-425.

van Deurs B, Holm PK, Kayser L, Sandvig K (1995) Delivery to lysosomes in the human carcinoma cell line Hep-2 involves an actin filament-facilitated fusion between mature endosomes and preexisting lysosomes. Eur J Cell Biol 66:309-323.

Waxman SG, Pappas GD (1969) Pinocytosis at postsynaptic membranes: electron microscopic evidence. Brain Res 14:240-244.

Westrum LE, Jones DH, Gray EG, Barron J (1980) Microtubules, dendritic spines and spine apparatuses. Cell Tissue Res 208:171-181. 